\title{
Tobacco and oral disease
}

\author{
N. W. Johnson,' ' C. A. Bain, ${ }^{2}$ and co-authors of the EU-Working Group on Tobacco and \\ Oral Health ${ }^{\dagger}$
}

\author{
This document was produced by the 'EU-Working Group' on \\ Tobacco and Oral Health' supported by the EU Commission \\ (the 'Europe Against Cancer' programme).
}

$\mathrm{T}$ There is overwhelming evidence that 1 tobacco usage produces harmful effects in the mouth. Among the various health staff groups, dentists are those most frequently in contact with the population. This fact renders dentists a favourable position in connection with tobacco intervention. Evidence shows that clinical interventions during dental care are as effective as in other healthcare settings. ${ }^{1}$

In this document the harmful effects of tobacco usage are briefly reviewed. The document is a revised version of a previously published report from the 'EU Working Group on Tobacco and Oral Health' ${ }^{2}$ in which a more detailed discussion and further references can be found. The Working Group is currently developing practical guidelines on how to help patients stop smoking.

\section{Tobacco and general diseases}

It appears that: about $30 \%$ of all cancer diseases and deaths; about $90 \%$ of all lung cancers; $30 \%$ of all cases of ischaemic heart disease and strokes; about $80 \%$ of myocardial infarctions before the age of 50 years; and $70 \%$ of chronic lung diseases (smoker's lung), are caused by tobacco smoking. ${ }^{3-5}$

The British doctors' study has shown that smokers are reducing their life length by an average of 7.5 years, irrespective of the type of tobacco smoked and the amount of daily smoking. ${ }^{6}$ The proportion of smokers reaching the age of 70 years was 59\% compared with $80 \%$

\footnotetext{
$1^{*}$ Department of Oral \& Maxillofacial Medicine \& Pathology, WHO Collaborating Centre for Oral Cancer \& Precancer, The Guy's, King's \& St Thomas' Schools of Medicine, Dentistry \& Biomedical Sciences, King's Dental Institute, Caldecot Road, London SE5 9RW; ${ }^{2}$ University of Glasgow

${ }^{*}$ Correspondence to: Professor Newell W Johnson email: newell.johnson@kcl.ac.uk

REFEREED PAPER

Received 20.05.99; Accepted 26.04.00

(C) British Dental Journal 2000; 189: 200-206
}

\section{In brief} periodontal treatment. within 5-10 years. practice prevention programme. among non-smokers. Thus, a very large proportion of smokers are dying before pensionable age.

The tar in tobacco is responsible for the development of cancer. The most important malignancy related to smoking is lung cancer. The 5-year survival rate is only between 5 and $10 \%$. A substantial fraction of cancers in the mouth, throat, oesophagus, urinary bladder and pancreas are also caused by tobacco smoking. ${ }^{3-5}$

The most disabling chronic lung disease related to smoking is chronic obstructive lung disease (COLD, 'smokers lung') comprising emphysema and chronic bronchitis. The terminal stage of COLD is increasing respiratory insufficiency and death. Smoking also increases the risk of developing asthma.
The risk of developing myocardial infarction is doubled in smokers compared with non-smokers. The risk increases with increasing consumption of tobacco and with other cardiovascular risk factors (cholesterol, hypertension, overweight). Arteriosclerosis is increased among smokers in other parts of the arterial tree and about $75-80 \%$ of all cases of intermittent claudication and aortic aneurysms are caused by smoking. The risk for developing myocardial infarction and stroke decreases rapidly after smoking cessation, and after 5-10 years ex-smokers have reached the same risk as never-smokers.

Several meta-analyses have shown that passive smoking can cause lung cancer as well as ischaemic heart disease. The risk related to passive smoking is, however, much lower than the risk related to active smoking.

Passive smoking can cause increased allergic reactions against specific allergens, reduced lung function, and increased asthmatic attacks in patients with asthma.

The EU-Working Group on Tobacco and Oral Health found:

- Smoking often results in discolourations of teeth and dental restorations.

- Halitosis, diminished taste and smell acuity are common side effects of smoking.

- Periodontal disease is increased both in prevalence and severity in smokers. Smoking cessation may halt disease progression and improve the outcome of

- Oral cancer and precancer occurs much more frequently in smokers than in nonsmokers. Smoking cessation significantly decreases the increased risk of oral cancer

- Dental implant failure rates are significantly higher in smokers than in non-smokers

- The entire dental team should be aware of the relationship between smoking and dental problems and should convey the message that non-smoking is the norm.

- Smoking counselling should be a fundamental part of the dental curriculum and any

${ }^{\dagger}$ The members of the Working Group are: Remy Allard (The Netherlands), A. P. Angelopoulos (Greece), Anja Ainamo (Finland), Antonio Azul (Portugal), Jose V. Bagan (Spain), Crawford Bain (United Kingdom), Annelise Bastholm (Denmark), Johann Beck-Mannagetta (Austria), M. Berengo (Italy), Joao Braga (Portugal), Hugo De Bruyn (Belgium), C. Cumeen (Ireland), Wolfgang Doneus (Austria), Richard Flachaire (France), Newell Johnson (United Kingdom), Aira Lahtinen (Finland), Jahn Legarth, coordinator (Denmark), Pedro Fernandez Leon (Spain), Karl-Heintz Löchte (Germany), Bernard McCartan (Ireland), Roger Monteil (France), Stavros Papanikolaou (Greece), Hans Preber (Sweden), Jesper Reibel, coordinator (Denmark), Peter Reichart (Germany), Andrea Sardella (Italy), Jos Schoenaers (Belgium), Isaäc van der Waal (The Netherlands), Örjan Åkerberg (Sweden) The document is based on contributions from members of the Working Group and from the following experts: Tony Axéll (Norway), David B. Ferguson (United Kingdom), Albert Hirsch

(France), Palle Holmstrup (Denmark), Robert E. Mecklenburg (USA), Poul Ebbe Nielsen (Denmark) 
Smoking during pregnancy may have serious consequences for the foetus as well as during the first years of life. Asthmatic bronchitis and infectious diseases in the upper respiratory tract among small children are to a great extent explained by the mother's smoking habits during pregnancy and/or after birth.

\section{Tobacco and oral disease}

\section{Aesthetics}

Smoking causes discolouration of teeth, dental restorations and dentures. ${ }^{7,8}$ The effect of smoking is more severe than that of the consumption of coffee and tea. ${ }^{9}$

\section{Saliva}

In the short term smoking increases the flow rate of the parotid gland. ${ }^{10,11}$ However, the data on long-term effects on salivary flow rates show no difference between smokers and non-smokers . ${ }^{12-14}$

The $\mathrm{pH}$ of saliva rises during smoking. ${ }^{15}$ Over longer time periods smokers have a lower $\mathrm{pH}$ in stimulated whole saliva, ${ }^{13}$ however another report showed no difference. ${ }^{16}$ Buffer capacity was found to be lower in smokers $^{12,17}$ although this was not confirmed in another study. ${ }^{14}$

The concentration of thiocyanate, a product present in tobacco smoke and in normal saliva, is increased in the saliva of smokers. ${ }^{18}$

\section{Dental caries}

Although smoking is a factor which has often been included in the analysis of caries rates there is insufficient evidence of any aetiological relationship. From the evidence mentioned above on the relation between tobacco usage and saliva composition this is not surprising. If thiocyanate concentrations are higher one might predict less dental caries. However, a possible lower salivary $\mathrm{pH}$ and buffering power, and the fact that there is a shift of the bacterial population towards lactobacillus and the cariogenic streptococci in smokers, ${ }^{12,13,19}$ might all argue for increased dental caries.

There are three recent surveys which link tobacco smoking with dental caries, one of different age strata ${ }^{20}$ and one of older subjects which identified tobacco smoking as a significant risk factor for tooth loss and dental caries, ${ }^{21}$ and one of teenagers which found all caries epidemiological data to be higher among tobacco users. ${ }^{22}$ However, the latter paper points out the danger of assuming that correlations necessarily imply a causative role.

\section{Smell and taste}

Many studies have shown that taste and smell acuity are affected by smoking. ${ }^{23,24}$ It should be mentioned here, that smoking is a common cause of halitosis.

\section{Wound healing}

Several studies have shown that tobacco influences wound healing in the mouth, eg after periodontal scaling and curretage, periodontal surgery or tooth extraction. ${ }^{25-27}$ The mechanism of impaired healing is likely associated with increased plasma levels of adrenaline and noradrenaline after smoking, leading to peripheral vasoconstriction. Several studies also show impaired PMN function in smokers compared with nonsmokers. $^{28}$

\section{Periodontal diseases:}

The role of smoking in periodontal diseases has been extensively studied for many years. An increasing amount of scientific data have demonstrated a clear association between smoking and the prevalence and severity of periodontal diseases, suggesting smoking as an important risk factor for periodontal disease. ${ }^{29-31}$

\section{Microflora and host response}

The exact mechanisms by which smoking affects the periodontal tissues are not known. Many epidemiological and clinical studies have reported smokers to harbour more supragingival plaque than nonsmokers. However, clinical studies have not reported any differences in plaque accumulation rate between smokers and non-smokers ${ }^{32}$ thereby indicating smoker's excess amount of plaque is probably caused by an inferior oral hygiene. One recent study reported that smokers harboured significantly higher levels of $B$. forsythus than non-smokers, although other studies on patients with periodontal disease have not reported any differences in the composition of the subgingival periopathogenic microflora. ${ }^{33-35}$

The greater prevalence and severity of disease in smokers might be explained by an altered host response. Smokers have demonstrated disturbances in immunoglobulin and cytokine levels, lymphocyte counts and impairment of the function of oral neutrophils. ${ }^{28,36,37}$

Besides possible specific effects from the periopathogenic bacteria and by an altered host response, there might be cytotoxic effects from nicotine on fibroblast function. ${ }^{38}$

\section{Gingivitis}

Many earlier studies on smoking and chronic gingivitis have reported both more gingival inflammation and more dental plaque and calculus in smokers. However, in recent studies, when the plaque level has been controlled for, smokers have demonstrated less gingival inflammation and less gingival bleeding when compared with non-smokers, indicating a suppressed gingival inflammation. ${ }^{32,39}$ These results, which suggest a lower bleeding propensity for smokers, are not surprising given the well known effect of nicotine exerting local vasoconstriction on peripheral circulation.

\section{Acute necrotizing ulcerative gingivitis (ANUG)}

Many studies have reported smokers to have a higher prevalence of ANUG than non-smokers. ${ }^{40}$ Recently, a similar relationship has been reported between smoking and ANUG-like lesions in HIV infected individuals. ${ }^{41}$ The results from these studies show a clear association between smoking and ANUG.

\section{Periodontitis}

The association between tobacco smoking and adult periodontitis has been studied during the past 20 years in well controlled studies on large groups of populations. ${ }^{31}$ The results from these studies suggest smokers to have an increased prevalence and severity of periodontitis, as reported by greater marginal bone loss, deeper periodontal pockets, more severe attachment loss and more teeth with furcation involvements (Fig. 1). 
Fig. I Smokers periodontitis. A 54-year-old female heavy smoker with severe adult periodontitis. Great gingival recession and discoloured root surfaces. Low gingival inflammation in spite of heavy plaque accumulation
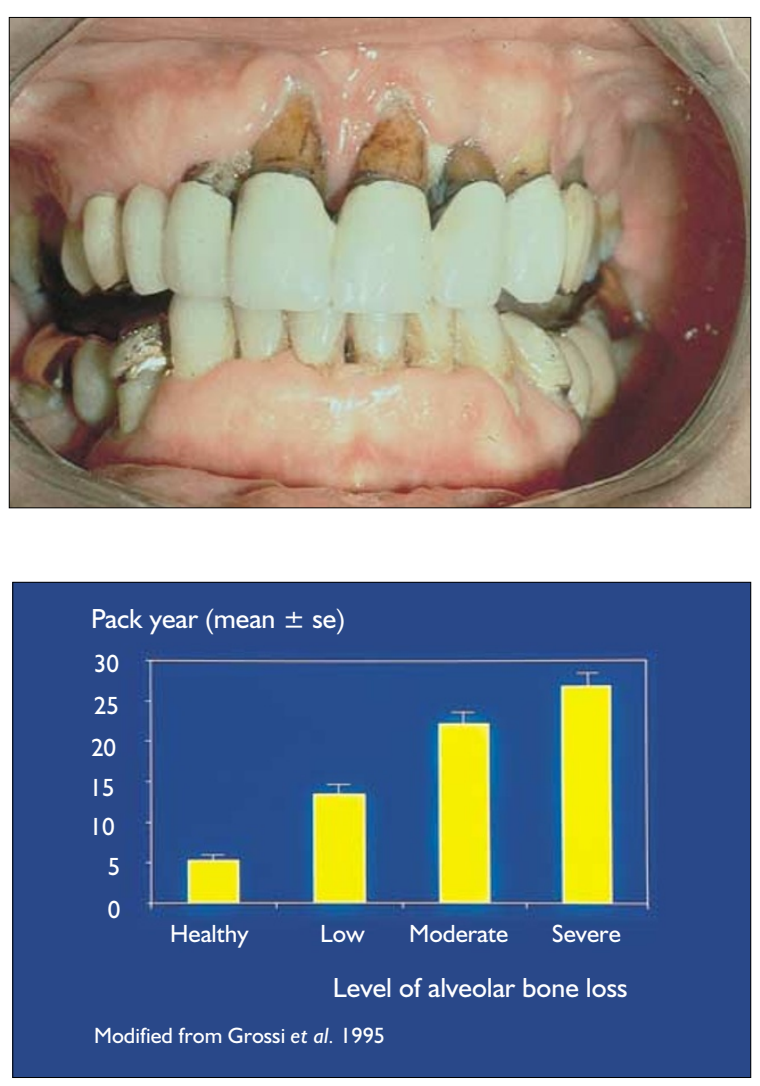

Fig. 2 Relationship between alveolar bone loss and amount of smoking (from ref. 48) study, 44 subjects who gave up smoking during a 10-year period, had significantly less marginal bone loss as compared with those 139 who smoked regularly during the period. ${ }^{49}$

The observations of these studies imply that smoking cessation may slow down or halt the progression of periodontal disease.

\section{Dental implants}

There is increasing evidence that tobacco is detrimental to both the initial and longterm success of dental implants, and that smoking cessation can be beneficial in improving implant success rates.

Smoking was found to be by far the most significant factor predisposing to implant failure. ${ }^{50}$ Failure rates were $4.8 \%$ in nonsmokers and $11.3 \%$ in smokers. When the maxilla was assessed separately failure rates in smokers exceeded $17.8 \%$ and were greatest with shorter implants. In a later study comparing implant failures prior to loading in the maxilla of smokers with non-smokers failure rates were $9 \%$ and $2 \%$ respectively. ${ }^{51}$

A recent study has also suggested an ongoing detrimental effect around the successfully integrated maxillary implants of smokers, with significantly greater bleeding index, mean peri-implant pocket depth, peri-implant inflammation and radiographically descernible mesial and distal bone loss. ${ }^{52}$ The authors suggest that these findings will lead to higher future failure rates in integrated implants in smokers. This position is supported by a 15-year prospective study of mandibular fixed implant prostheses in which it was found that smoking correlated more strongly with

\section{Periodontal therapy}

Clinical studies have demonstrated that smoking adversely affects the outcome of various modalities of periodontal therapy. Studies on surgical as well as non-surgical therapy report inferior results in smoking patients. ${ }^{44,45}$ Smokers have also been reported to have poorer success rates following periodontal regenerative surgery. ${ }^{46}$ Furthermore, refractory periodontitis cases, ie patients who do not respond as expected following therapy exhibiting continuing progression of disease, are heavily overrepresented in smokers. ${ }^{47}$

Fig. 3 Carcinoma of the floor of the mouth in a heavy smoker

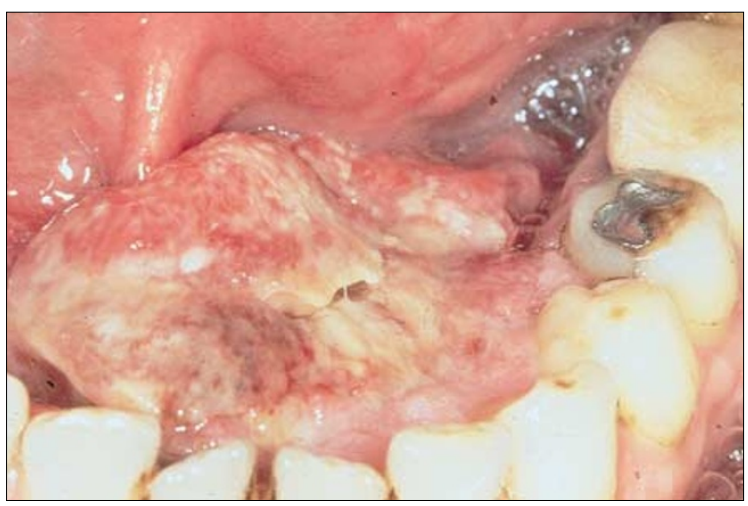




\section{PRACTICE tobacco intervention}

Fig. 4 Relative risks of oral cavity cancer by daily consumption of alcohol and cigarettes for men (from ref. 58)

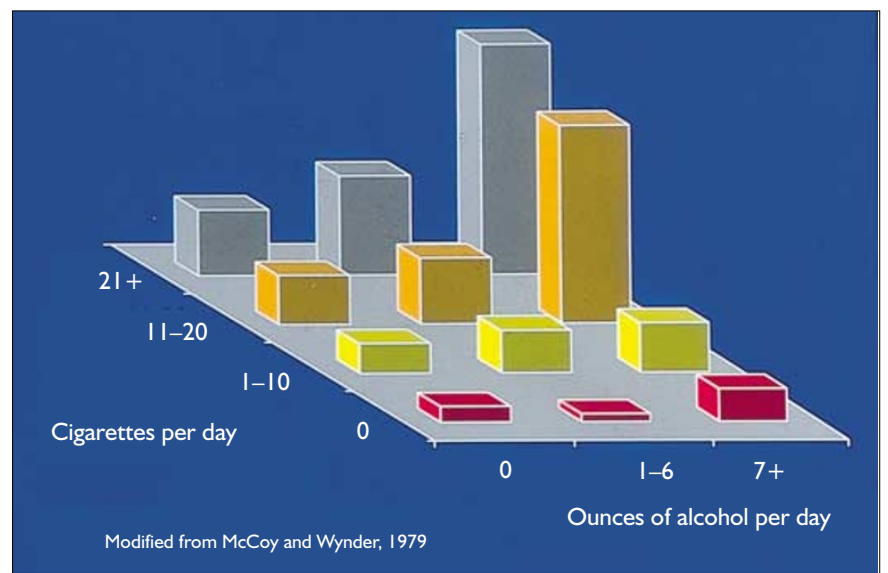

marginal bone loss around implants than even poorer oral hygiene. ${ }^{53}$

\section{Smoker cessation}

Following a protocol of complete cessation for one week before and eight weeks after initial implant placement surgery, a significant reduction in implant failure in the group who stopped smoking was found when compared with smokers who continued the habit. ${ }^{54}$ The group who followed the cessation protocol had no significant difference in their failure rate when compared with non-smokers over the same period.

\section{Oral mucosal diseases}

Tobacco use is associated with several changes in the oral mucous membranes ranging from innocent and reversible lesions, such as smoker's palate, to oral cancer. The innocent lesions offer an excellent opportunity to initiate a discussion on tobacco.

Oral cancer

Tobacco smoke has a direct carcinogenic effect on the epithelial cells of the oral mucous membranes. It has been well demonstrated that there is a dose-response relationship for tobacco use and the risk of the development of oral cancer (Fig. 3). From earlier studies it appeared that those who smoked pipe or cigars probably experienced a risk of oral cancer lower than that of cigarette smokers. ${ }^{55}$ However, it has been concluded recently that the risks of oral cancer are similar for cigar smokers and cigarette smokers. ${ }^{56}$ Cessation of cigarette smoking eliminates the increased risk of development of oral cancer within 5-10 years. ${ }^{57}$

Smokers who do not use alcohol have a two- to four-fold risk of developing oral cancer than tobacco and alcohol abstainers; the oral cancer risk of smokers who are heavy drinkers is 6-15 times greater than that of non-smokers/non-drinkers (Fig. 4)..$^{55,57-59}$ Alcohol increases the permeability of the oral mucous membranes, thereby
Fig. 5 Leukoplakia of the commissure in a heavy smoker

Fig. 6 Malignant transformation
of a leukoplakia of the tongue
in a smoker

probably enhancing the carcinogenic effect of tobacco products. ${ }^{60}$

\section{Oral precancer}

Of the potentially malignant lesions of the oral mucous membranes, the so-called leukoplakia is the most common (Figs 5 and 6). Leukoplakia occurs six times more frequently in smokers than in non-smokers. ${ }^{61}$ There is a dose-response relationship between tobacco usage and the prevalence of oral leukoplakia. Reducing or cessation of tobacco use may result in the regression or disappearance of oral leukoplakia. ${ }^{62,63}$

\section{Smoker's palate}

Heavy smokers, especially pipe-smokers, frequently develop white changes in the hard palate, often combined with multiple red dots sometimes located centrally in small elevated nodules (Fig. 7). ${ }^{64}$ Smoker's palate is asymptomatic and it disappears shortly after cessation of the smoking habit (Fig. 8). It is not premalignant. The palatal keratosis associated with reverse smoking, as it can be seen in some
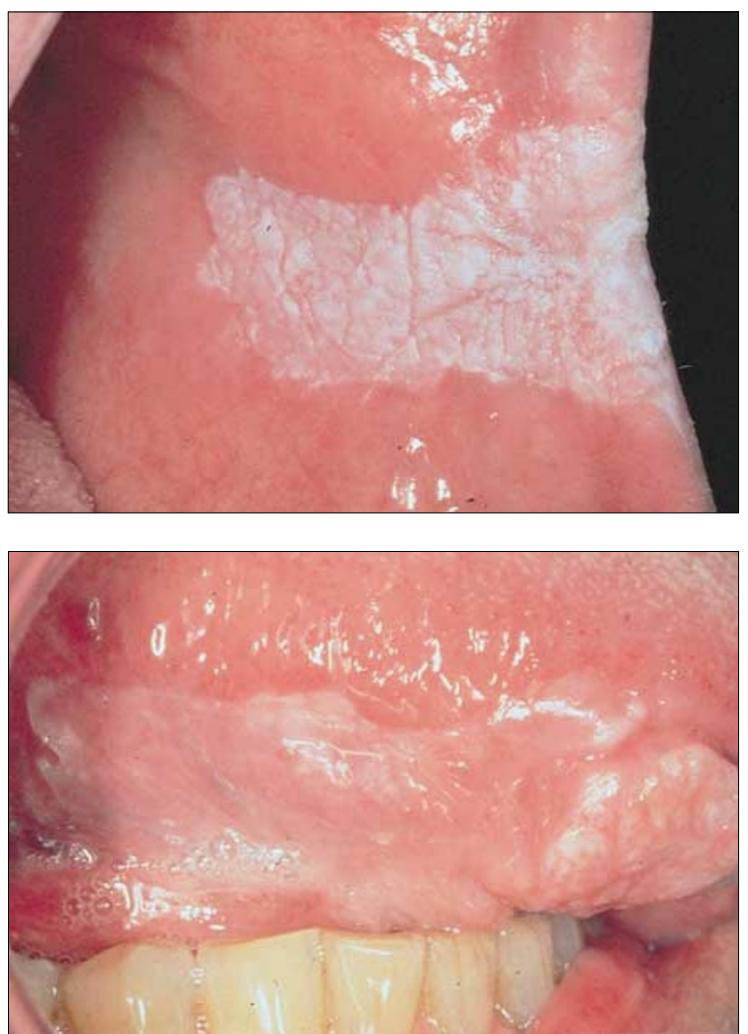
Fig. 7 Smoker's palate in a pipe smoker

Fig. 8 The same patient 2 months after smoking cessation
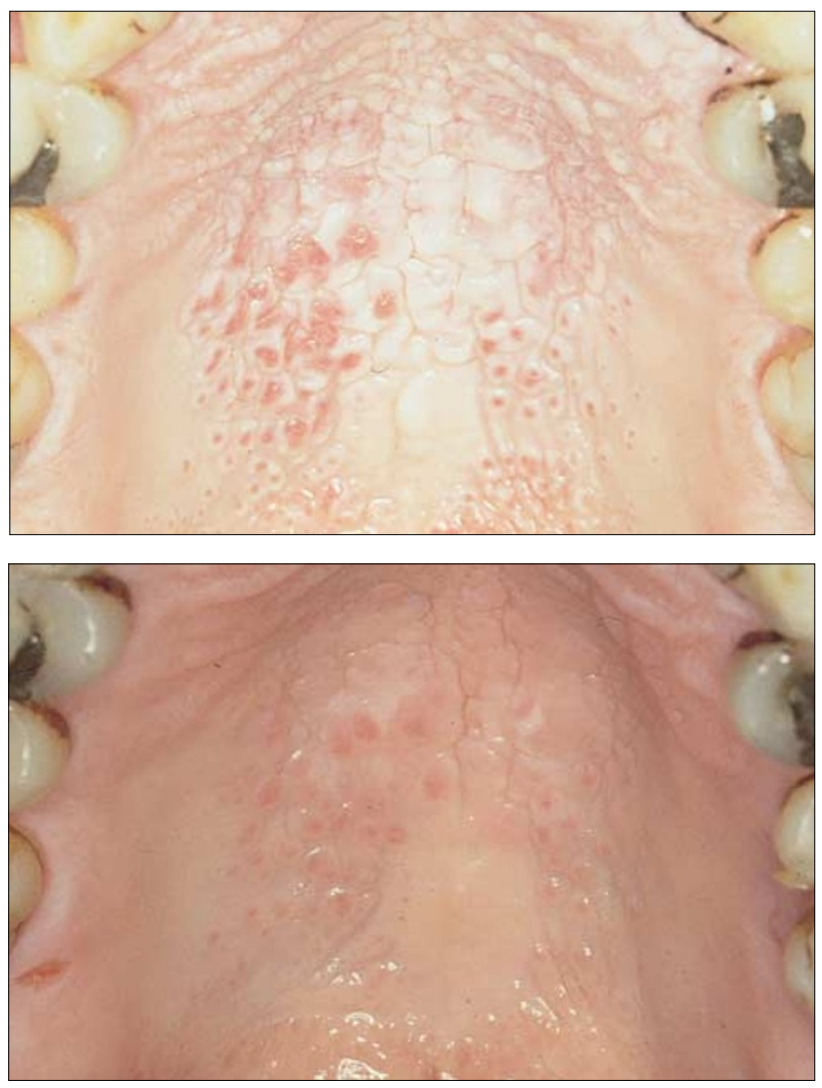

parts of the world, is a premalignant lesion. ${ }^{65}$

\section{Smoker's melanosis}

Melanin pigmentation of the oral mucous membranes is normally seen in coloured races. In north European Caucasians, however, it is far less prevalent (about 10\%) and normally with a subtle appearance. Heavy cigarette smokers show a pigmentation prevalence of about $30 \%{ }^{66}$ thus giving rise to the designation smoker's melanosis ${ }^{67}$ which is most prevalent on the attached gingiva (Fig. 9). There are no symptoms, the change is not premalignant, and the pigmentation is reversible although it usually takes a year or more after cessation of the smoking habit. ${ }^{66,68}$

\section{Oral candidosis}

Several factors predispose to oral candidosis. Whether tobacco smoking is one of them has been discussed for years, but during the past two decades a number of studies have found that smoking, either alone or in combination with other factors, appears to be an important predisposing factor for oral candidosis although the exact pathogenic influence of smoking is not revealed. ${ }^{69-71}$

Patients continuing the smoking habit after cessation of antimycotic therapy had relapses of the candidal infection in all
Fig. 9 Smoker's melanosis in a heavy cigarette smoker cases. ${ }^{69}$ Furthermore, it is a clinical experience that some candida infections disappear following smoking cessation alone .

Oral smokeless tobacco-induced changes The use of smokeless tobacco is well known to induce wrinkled changes in the oral mucosa at the site where the quid is placed. ${ }^{72-75}$ The changes are usually discreet with a colour similar to the surrounding oral mucous membranes or whitish-yellowish to brown. The changes seem to be reversible. ${ }^{76}$ Gingival recessions may also be seen in users of smokeless tobacco at the site where the quid is placed. $^{72}$

The relationship between the use of oral smokeless tobacco and cancer development has been amply discussed. Snuff use as practiced in Scandinavia carry none or very low risks for development of oral cancer. ${ }^{73}$ Differences in habits and between products around the world are probably important when evaluating the harmful effects of oral smokeless tobacco, so that a general statement on this subject cannot be made. However, many forms of oral smokeless tobacco in common use in Asia, the Middle East, and North Africa are carcinogenic.

\section{Tobacco intervention and the dentist} Helping patients to stop using tobacco may be the single most important service dentists can provide for their patients' general health. ${ }^{77}$

Dentists probably have the highest access to 'healthy' smokers in the healthcare sys-

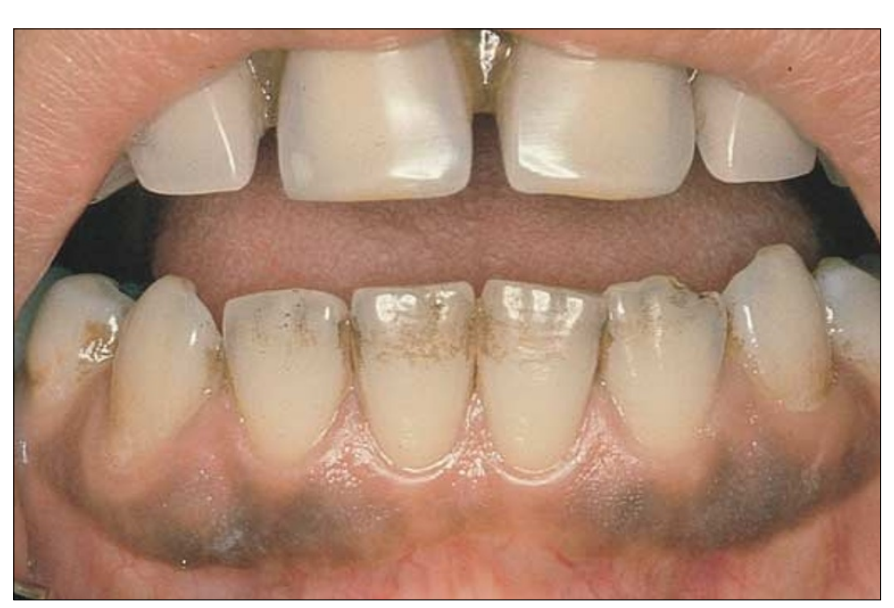


tem and a direct professional interest because of the harmful effects of smoking in the oral cavity. The term 'tobacco intervention' includes at least three different strategies: ${ }^{78}$

- To reduce recruitment of new tobacco users - mainly young people

- To support and assist tobacco users who wish to quit

- To avoid that non-smokers - including the foetus - suffer because of other people's smoking.

Preferably, dentists should be competent in all three areas. The phrase 'Helping patients and the public to be tobacco free' encompasses these components.

The FDI has adopted a Position Statement on Tobacco in 1996 dealing with: ${ }^{79}$

- Tobacco in daily practice

- Tobacco in all education

- Protect the children

- Prevent the initiation.

\section{Tobacco in daily practice}

The use of tobacco is harmful to general health, as it is a common cause of addiction, preventable illness, disability, and death. The use of tobacco also causes an increased risk for oral cancer, periodontal diseases and other deleterious oral conditions, and it adversely affects the outcome of oral care.

The FDI urges its Member Associations and all oral health professionals to take decisive actions to reduce tobacco use and nicotine addiction among the general pubic.

The FDI also urges all oral health professionals to integrate tobacco use prevention and cessation services into their routine and daily practice.

All National Dental Associations should be encouraged to adopt tobacco-free policies which could be based on the FDI Position Statement. The British Dental Association concurs.

The entire dental team should be aware of the relationship between smoking and dental problems. The clinic staff should be encouraged to actively participate in tobacco intervention routines and to convey the message that non-smoking is the norm. ${ }^{80}$

Thus, current facts on tobacco and oral health and smoking counselling should be a fundamental part of the dental curriculum and any practice prevention programme.

The goal is to ensure that all patients who smoke are routinely identified, monitored, and appropriately taken care of. The EU Working Group on Tobacco and Oral Health is currently developing practical guidelines on how to help patients stop smoking, based on that recently published by the UK Health Education Authority. ${ }^{81}$

1 MacGregor I D M. Efficacy of dental health advice as an aid to reducing cigarette smoking. Br Dent J 1996; 180: 292-296.

2 EU Working Group on Tobacco and Oral Health: Meeting Report. Oral Dis 1998; 4: 48-67.

3 Fielding J E. Smoking: health effects and control. N Engl J Med 1985; 313: 491-498.

4 La Vecchia C, Boyle P, Franceschi S et al. Smoking and cancer with emphasis on Europe. Eur J Cancer 1991; 27: 94-104.

5 Peto R, Lopez A D, Boreham J, Thun M, Health C Jr, Doll R. Mortality from smoking worldwide. Br Med Bull 1996; 52: 12-21.

6 Doll R, Peto R, Wheatley K, Gray R, Sutherland I. Mortality in relation to smoking: 40 years' observation on male British doctors. Br Med J 1994; 309: 901-911.

7 Asmussen E, Hansen E K. Surface discoloration of restorative resins in relation to surface softening and oral hygiene. Scand J Dent Res 1986; 94: 174-177.

8 Murray I D, McCabe J F, Storer R. The relationship between the abrasivity and cleaning power of the dentifrice-type denture cleaners. Br DentJ 1986; 161: 205-208.

9 Ness L, Rosekrans D L, Welford J F. An epidemiologic study of factors affecting extrinsic staining of teeth in an English population. Community Dent Oral Epidemiol 1977; 5: 55-60.

10 Barylko-Pikielna N, Pangborn R M, Shannon I L. Effect of cigarette smoking on parotid secretion. Arch Environ Health 1968; 17: 731-738.

11 Pangborn R M, Sharon I M. Visual deprivation and parotid response to cigarette smoking. Physiol Behavior 1971; 6: 559-561.

12 Heintze U. Secretion rate, buffer effect and number of lactobaccilli and streptococcus mutans of whole saliva of cigarette smokers and non-smokers. Scand J Dent Res 1984; 92: 294-301.

13 Parvinen T. Stimulated salivary flow rate, $\mathrm{pH}$ and lactobacillus and yeast concentrations in non-smokers and smokers. Scand J Dent Res 1984; 92: 315-318.

14 Olsen B L, McDonald J L, Gleason M J et al. Comparison of various salivary parameters in smokers before and after the use of a nicotinecontaining chewing gum. J Dent Res 1985; 64: 826-830.
15 Kenney E B, Saxe R D, Bowles R D. The effect of cigarette smoking on anaerobics in the oral cavity. J Periodont Res 1975; 46: 82-85.

16 Courant P. Effect of smoking on the antilactobacillus system in saliva. Odontol Revy 1967; 18: 251-261.

17 Wikner S, Söder P O. Factors associated with salivary buffering capacity in young adults in Stockholm. Scand J Dent Res 1994; 102: 50-53.

18 Tenovuo J, Makinen K K. Concentration of thiocyanate and ionisable iodine in saliva of smokers and non-smokers. J Dent Res 1976; 55: 661-663.

19 Sakki T, Knuuttila M. Controlled study of the association of smoking with lactobacilli, mutans streptococci and yeasts in saliva. Eur J Oral Sci 1996; 104: 619-622.

20 Axelsson P, Paulander J, Lindhe J. Relationship between smoking and dental status in 35-, 50-, 65-, and 75-year-old individuals. J Clin Periodontol 1998; 25: 297-305.

21 Jette A M, Feldman H A, Tennstedt S L. Tobacco use: a modifiable risk factor for dental disease in the elderly. Am J Public Health 1993; 83: 1271-1276.

22 Hirsch J M, Livian G, Edward S et al. Tobacco habits among teenagers in the city of Göteborg, Sweden, and possible association with dental caries. Swed Dent J 1991; 15: 117-123.

23 Fortier I, Ferraris J, Mergler D. Measurement precision of an olfactory percepection threshold test for use infield studies. Am J Indust Med 1991; 20: 495-504.

24. Pasquali B. Menstrual phase, history of smoking, and taste discrimination in young women. Percept Motor Skills 1997; 84: 12431246.

25 Preber H. Smoking and periodontal disease. Stockholm: Karolinska Institute, 1986.

26 Meechan J G, MacGregor G M, Rogers S M et al. The effects of smoking on immediate postextraction socket filling with blood and on the incidence of painful sockets. Br J Oral Maxillofac Surg 1988; 26: 402-409.

27 Miller P D. Regenerative and reconstructive periodontal surgery. Dent Clin North Amer 1988; 32: 287-312.

28 Kenney E B, Kraal J H, Saxe S R, Jones J. The effects of cigarette smoke on human polymorphonuclear leukocytes. J Periodontol Res 1977; 12: 227-234.

29 Bergström J, Preber H. Tobacco use as a risk factor. J Periodontol 1994; 65: 545-550.

30 Position Paper. The research, science and therapy commitee of the American Academy of Periodontology. Tobacco use and the periodontal patient. J Periodontol 1996; 67: 51-56.

31 Salvi Ge, Lawrence H P, Offenbacher S, Beck J D. Influence of risk factors on the pathogenesis of periodontitis. Periodontol 2000 1997; 14: 173-201.

32 Bergström J, Preber $\mathrm{H}$. The influence of cigarette smoking on the development of experimental gingivitis. J Periodont Res 1986; 21: 668-676.

33 Zambon J J, Grossi S G, Machtei E E, et al. 
Cigarette smoking increases the risk for subgingival infection with periodontal pathogens. J Periodontol 1996; 67: 1050-1054.

34 Preber H, Bergström J, Linder L E. Occurrence of periopathogens in smoker and nonsmoker patients. J Clin Periodontol 1992; 19: 667-671.

35 Renvert S, Dahlen G, Wikström M. The clinical and microbiological effects of non-surgical periodontal therapy in smokers and nonsmokers. J Clin Periodontol 1998; 25: 153-157.

36 Johnson J D, Houchens D P, Kluwe W M, Craig D K, Fisher G U. Effects of mainstream and environmental tobacco smoke on the immune system in animals and humans. A review. Crit Rev Toxicol 1990; 20: 369-375.

37 Boström L, Linder L E, Bergström J. Influence of smoking on the outcome of periodontal surgery. A 5-year follow-up. J Clin Periodontol 1998; 25: 194-201.

38 Tipton D A, Dabbous M K. Effects of nicotine on proliferation and extracellular matrix production of human gingival fibroblasts in vitro. J Periodontol 1995; 66: 1056-1064.

39 Danielsen B, Manji F, Nagelkerke N, Fejerskov $\mathrm{G}$, Baelum V. Effect of cigarette smoking on the transition dynamics in experimental gingivitis. J Clin Periodontol 1990; 17: 159-164.

40 Kardachi B J R, Clarke N G. Aetiology of acute necrotizing gingivitis: a hypothetical explanation. J Periodontol 1974; 45: 830-832.

41 Swango P A, Kleinman D V, Konzelmzn J L. HIV and periodontal health: A study of military personnel with HIV. JADA 1991; 122: 49-54.

42 Ismail A I, Morrison E C, Burt B A, Caffesse R G, Kavanagh M T. Natural history of periodontal disease in adults: Findings from the Tecumseh periodontal disease study, 195887. J Dent Res 1990; 69: 430-441.

43 Mullally B H, Linden G J. Molar furcation involvement associated with cigarette smoking in periodontal referrals. J Clin Periodontol 1996; 23: 658-661.

44 Preber H, Bergström J. Effect of tobacco smoking on periodontal healing following surgical therapy. J Clin Periodontol 1990; 17: 324-328.

45 Kaldahl W D, Johnson G K, Patil K D, et al. Levels of cigarette consumption and response to periodontal therapy. J Periodontol 1996; 67: 675-682.

46 Trombelli L, Scabbia A. Healing response of gingival recession defects following guided tissue regeneration in smokers and nonsmokers. J Clin Periodontol 1997; 24: 529-533.

47 MacFarlane G, Herzberg M, Wolf L, Hardie N Refractory periodontitis associated with abnormal polymorphonuclear phagocytosis and cigarette smoking. J Periodontol 1992; 63: 908-913.

48 Grossi S G, Genco R J, Machtei E E. Assessment of risk for periodontal disease. II. Risk indicators for alveolar bone loss. J Periodontol 1995; 66: 23-29.
49 Bolin A, Eklund G, Frithiof L, Lavstedt S. The effect of changed smoking habits on marginal alveolar bone loss. Swed Dent J 1993; 17: 211216.

50 Bain C A, Moy P K. The association between the failure of dental implants and cigarette smoking. Int J Oral Maxillofac Implants 1993; 8: 609-615.

51 De Bruyn H, Collaert B. The effects of smoking on early implant failure. Clin Oral Impl Res 1994; 5: 260-264.

52 Haas R, Haimbock W, Mailath G, et al. The relationship of smoking on peri-implant tissue: a retrospective study. J Prosth Dent 1996; 76: 592-595.

53 Linquist L W, Carlsson G E, Jemt T. A prospective 15-year follow-up study of mandibular fixed prostheses supported by osseointegrated implants. Clin Oral Implant Res 1996; 7: 329-336.

54 Bain C A. Smoking and implant failure Benefits of a smoking cessation protocol. Int J Oral Maxillofac Implants 1996; 11: 756-759.

55 Wynder E L, Mushinski M H, Spivah J C. Tobacco and alcohol consumption in relation to the development of multiple primary cancers. Cancer 1977; 40: 1872-1878.

56 NCI Monograph 9: Cigars: Health Effects and Trends. NIH Publication No. 98-4302, Bethesda US Public Health Service, February 1998.

57 Blot W J, McLaughlin J K, Winn D M et al. Smoking and drinking in relation to oral and pharyngeal cancer. Cancer Res 1988; 48 : 3282-3287.

58 McCoy G D, Wynder E L. Etiological and preventive implications in alcohol carcinogenesis. Cancer Res 1979; 39: 2844 2850.

59 Kato I, Nomura A M Y. Alcohol in the aetiology of upper aerodigestive tract cancer. Oral Oncol, Eur I Cancer 1994; 30B: 75-81.

60 Squier C A, Cox P, Hall B K. Enhanced penetration of nitrosonornicotine across oral mucosa in the presence of ethanol. J Oral Pathol 1986; 15: 276-279.

61 Baric J M, Alman J E, Feldman R S et al. Influence of cigarette, pipe, and cigar smoking, removable partial dentures, and age on oral leukopiakia. Oral Surg Oral Med Oral Pathol 1982; 54: 242-249.

62 Roed-Petersen B. Effect on oral leukoplakia of reducing or increasing tobacco smoking. Acra Dermatovenerol (Stockholm) 1981; 62: 164-167.

63 Gupta P C, Murti P R, Bhonsle R B et al. Effect of cessation of tobacco use on the incidence of oral mucosal lesions in a 10-yr follow-up study of 12,212 users. Oral Dis 1995; 1: 54-58.

64 Axéll T. Occurrence of leukoplakia and some other oral white lesions among 20,333 adult Swedish people. Community Dent Oral Epidemiol 1987; 15: 46-51.

65 Mehta F S, Jainawalla P N, Daftary D K et al. Reverse smoking in Andra Pradesh, India: variability of clinical and histologic appearance of palatal changes. Int J Oral Surg 1977; 6 : 75-83.

66 Axéll T, Hedin C A. Epidemiologic study of excessive oral melanin pigmentation with special reference to the influence of tobacco habits. Scand J Dent Res 1982; 90: 434-442.

67 Hedin C A. Smoker's melanosis. Occurrence and localization in the attached gingiva. Arch Dermatol 1977; 113: 1533-1538.

68 Hedin C A, Pindborg J J, Axéll T. Disappearance of smoker's melanosis after reducing smoking. J Oral Pathol Med 1993; 22: 228-230.

69 Holmstrup P, Bessermann M. Clinical, therapeutic, and pathogenic aspects of chronic multifocal candidiasis. Oral Surg Oral Pathol Oral Med 1983; 56: 388-395.

70 ArendorfT M, Walker D M, Kingdom R J, Roll J R S, Newcombe R G. Tobacco smoking and denture wearing in oral candidal leukoplakia. Br Dent J 1983; 155: 340-343.

71 Arendorf T M, Walker D M. Tobacco smoking and denture wearing as local aetiological factors in median rhomboid glossitis. Int J Oral Surg 1984; 13: 411-415.

72 Andresson G. Snuff-induced changes associated with the use of loose and portionbagpacked Swedish moist snuff. A clinical, histological and follow-up study. Thesis. Swed Dent J 1991; 15: (Suppl 75) S1-S9.

73 Axéll T. Oral mucosal changes related to smokeless tobacco usage: research findings in Scandinavia. Oral Oncol, Eur J Cancer 1993; 29B: 299-302.

74 Axéll T, Mörnstad H, Sundström B. The relation of the clinical picture to the histopathology of snuff dipper's lesion in a Swedish population. J Oral Pathol 1976; 5: 229-236.

75 Greer R O, Poulson T C. Oral tissue alterations associated with the use of smokeless tobacco by teenagers. Oral Surg Oral Pathol Oral Med 1983; 56: 275-284.

76 Larsson A, Axéll T, Andersson G. Reversibility of snuff dippers' lesion in Swedish moist snuff users: a clinical and histologic follow-up study. J Oral Pathol Med 1991; 20: 258-264.

77 Mecklenburg R E, Greenspan D, Kleinman D V, et al. Tobacco effects in the mouth. NIH Publication 92-3330, 1992.

78 WHO Guidelines for Controlling and Monitoring the Tobacco Epidemic. Geneva: Tobacco or Health Programme, WHO, 1996.

79 FDI. Position Statement on Tobacco. FDI World. London: FDI World Dental Press, NovemberDecember 1996.

80 Smith S E, Warnakulasuriya K A A S, Feyerabend L, Belcher M, Cooper D, Johnson $\mathrm{N}$ W. A smoking cessation programme conducted through dental practices in the UK. Br Dent J 1998; 185: 299-303.

81 Watt R, Robinson M. Helping smokers to STOP: A guide for the dental team. London: Health Education Authority, 1999. 